\title{
Applications of Time-Temperature Integrator (TTI) as a Quality Indicator of Grounded Pork Patty
}

\author{
Ji-Yeon Chun ${ }^{1}$, Mi-Jung $\mathrm{Choi}^{2}$, Seung Ju Lee ${ }^{3}$, and Geun-Pyo Hong* \\ Department of Bio-Industrial Technologies, Konkuk University, Seoul 143-701, Korea \\ ${ }^{1}$ Department of Food Science and Biotechnology of Animal Resources, Konkuk University, Seoul 143-701, Korea \\ ${ }^{2}$ Department of Bioresources and Food Science, Konkuk University, Seoul 143-701, Korea \\ ${ }^{3}$ Department of Food Science and Technology, Dongguk University-Seoul, Seoul 100-715, Korea
}

\begin{abstract}
Time-temperature integrators (TTIs) are simple and cost-efficient tools which may be used to predict food quality. Enzymatic TTIs are devised to indicate food quality in the form of color alterations from green to red, based on the cumulative impacts of temperature and time period on the enzymatic reactions. In this study, the quality of ground beef patties was investigated for the parameters of $\mathrm{pH}$ levels, color, $\mathrm{VBN}$, water holding capacity, and total microbial counts, depending on various storage temperatures $\left(5,15\right.$, and $\left.25^{\circ} \mathrm{C}\right)$. TTIs were attached to the surface of the ground beef patties in order to evaluate the degree of correlating colorimetric changes with the determined quality parameters. Through the Arrhenius equation, activation energy and constant reaction rates of TTI, VBN, and total microbial counts were calculated as to observe the relationship between enzymatic reactions of the TTI and food spoilage reactions of the ground beef patties. VBN and total microbial counts were already increased to reach decomposition index (VBN: 20, total microbial count: 7-8 Log CFU/g) of meat at middle stage of storage period for each storage temperature. Although activation energy of TTI enzymatic reactions and food spoilage reactions of the ground beef patties were similar, the change of TTI color was not a coincidence for food spoilage at $5^{\circ} \mathrm{C}$ and $15^{\circ} \mathrm{C}$ of storage temperature. It was suggested that TTI should be designed individually for storage temperature, time, type of meat, or decomposition index of meat.
\end{abstract}

Key words: time-temperature integrator, beef patty, storage, quality indicator

\section{Introduction}

Throughout history, food products and services that promote personal well-being have been sought. Consumers have demanded quality factors of food especially in the meat product industry as consumption of meat is gradually increased. Hence, it is sought to control the quality of meat at every stage of production, such as the rearing of the animals, slaughter, distribution and storage. Quality control is helpful both to the consumer and to the manufacturer, because consumer is assured a high quality meat product and the manufacturer can reduce economic loss by decreasing unexpected spoilage of meat products (Bruckner et al., 2013; Taoukis et al., 1999; Vaikousi et

*Corresponding author: Geun-Pyo Hong, Department of BioIndustrial Technologies, Konkuk University, Seoul 143-701, Korea. Tel: 82-2-450-3674, Fax: 82-2-455-1044, E-mail: genpro @konkuk.ac.kr al., 2009).

Temperature-sensitive products are carried through the cold-chain and are used to check the history of storage and delivery conditions until the point of consumption. Many food processing enterprises have applied Hazard Analysis Critical Control Point system (HACCP) process to keep up with customer needs. However, it is impractical to test product qualities such as chemical, physical, or microbial properties before purchasing in the market. Consumers can merely confirm that the designated expiry date is appropriate and personally observe for color, ion sealed packages, and malodour, when available. (Byeon et al., 2009; Shin et al., 2006). Moreover, thermal processing has been well-known as an effective way of preventing or eliminating photogenic bacteria or viruses from food products such as meat, fish, and poultry products, but this type of processing is one of the last control points in HACCP (Orta-Ramirez and Smith 2002; Van Loey et al., 1996). Obviously, uncooked meat products are 
exposed to various environmental stresses such as temperature, oxygen, light, and so on, before cooking.

Forecasting systems for food quality have been developed over past decades. Time-temperature integrators (TTIs) are used to predict food quality and it has been considered that it is essential tool in food groups. TTIs are devised to show food quality as a color alteration which occurs at varying rates due to exposure to varying temperature. Moreover, TTIs have low-cost and high-efficiency. (Ellouze et al., 2011; Kim et al., 2012b). Three types of TTI have been developed, which are based on diffusion, enzyme, and polymer sensors, which are classified by reaction material or method. The reaction can be a physical, chemical or enzymatic irreversible change (Park et al., 2009; Vaikousi et al., 2009). Vitsab ${ }^{\circledR}$ Smart Labels TTIs, which are highly efficient and simple, were used in this study. This TTI is based on enzymatic reaction and uses lipase. The enzyme induces lipolysis which affects a decrease of $\mathrm{pH}$ that causes a color-change of the indicator from green to red (Kim et al., 2012a; Smolander et al., 2004). Finally we aim to recognize the state of product quality through the color of the TTI. There are many instances of applications of TTI within the food industry (Bobelyn et al., 2006; Claeys et al., 2002; Giannakourou and Taoukis 2002; Shin et al., 2006; Taoukis et al., 1999; Vaikousi et al., 2009).

Even if the application of TTIs on food products has increased because of their cost-effectiveness, simplicity, and ease-of-use, they still must be calibrated to the chemical, physical, microbial or sensory properties of the products to which they are applied $(\mathrm{pH}$, color, VBN, TBA, water holding capacity, total microbial count, sensory evaluation etc.) depending on the storage period and processing method (Jeong et al., 2006; Jin et al., 2002; Kim et al., 2012b; Shin et al., 2006). These methods of determination take time, cost and skilled technicians to observe the freshness of meat products, and therefore, it is of great advantage to carry out a detailed investigation of the relationship between TTI and quality of meat products, using the TTI thereafter. In this study, the objective was to investigate correlation between TTI and ground beef patty quality. Therefore, we observed changes of TTI's color and meat quality such as meat color, $\mathrm{pH}, \mathrm{VBN}$, waterholding capacity, and total microbial count, as measured during storage under variable temperature conditions. Arrhenius activation energy was calculated to represent the correlation between TTI and GBP quality at the same temperature and period.

\section{Materials and Methods}

\section{Materials}

Time-temperature integrators (TTI, Vitsab ${ }^{\circledR}$ Smart Labels, Sweden) which are an enzymatic reaction type TTI were donated by Vitsab International. Ground Beef was obtained from a meat grocery in the Hwayang Market. Potassium carbonate and Brunswick solution was purchased from SAMCHUN Chemical Co. (Korea). Sulfuric acid was provided by PFP (PFP Matunoen chemicals Ltd, Japan) and sodium hydroxide was bought from SHOWA (SHOWA, Japan). For the microbial test, plate count agar (PCA) was obtained from Difco (Becton Dickinson and Company, USA).

\section{Sample preparation}

Seventy grams of ground beef was formed using a petri dish (Internal dimension: $85.6 \mathrm{~mm} \times 12.6 \mathrm{~mm}$, SPL, Korea) to result in a uniform and reproducible sample shape and volume. TTIs were attached to the middle of the surface of the ground beef patties (GBPs). GBPs with attached TTI were then stored at $5^{\circ} \mathrm{C}, 15^{\circ} \mathrm{C}$, or $25^{\circ} \mathrm{C}$ for predetermined storage periods. Change in GBPs quality and TTI was observed at certain periods in triplicate. Observations of GBPs quality ceased when the $a^{*}$-value of TTIs (1st condition) was over 20-25, or when VBN (2nd condition) was greater than 20 , which was based on the findings of a previous research (Chun et al., 2009).

\section{Color}

CIE Lab color values were measured from the surface of GBPs with a color reader (CR-10, Konica Minolta Sensing Inc., Japan) which was calibrated using a standard white plate. The CIE $L^{*}, a^{*}$, and $b^{*}$ values were designated as indicators of lightness, redness, and yellowness, respectively. The samples were determined and three measurements were taken from the surface of each sample. $a^{*}$ values were then considered as quality attribute depending on storage temperature. The change of $a^{*}$-value was calculated over time to evaluate the constant reaction rate and activation energy, using the Arrhenius equation.

\section{Volatile basic nitrogen (VBN)}

VBN of samples was measured by Conway's Micro diffusion method of Korean Food Standards Codex (KFDA, 2012). Three Conway's tools were cleaned with a neutral detergent to remove any containment. To the edge of the outer ring of each unit was applied sealing agent. Five 
grams of GBP from a homogenate was mixed with $25 \mathrm{~mL}$ distilled water and was then filtered. The $1 \mathrm{~mL}$ of filtrate was put into the lower part of outer ring and $1 \mathrm{~mL}$ of saturated $\mathrm{K}_{2} \mathrm{CO}_{3}$ solution was carefully pipetted into the upper part of outer ring. One $\mathrm{mL}$ of $0.01 \mathrm{~N} \mathrm{H}_{2} \mathrm{SO}_{4}$ was added to the inner ring of the unit and immediately the units were covered and closed with clip. Solution of outer ring was mixed carefully to prevent any entering the inner ring. The Conway diffusion cell was filled with the filtrate of GBPs and was kept at $25^{\circ} \mathrm{C}$ for $1 \mathrm{~h}$. One drop of Brunswick solution was added to the inner ring of the unit and the filtrate of GBPs was then titrated with $0.01 \mathrm{~N} \mathrm{NaOH}$ solution. The VBN value was calculated as

$$
\operatorname{VBN}(\mathrm{mg} \%)=0.14 \times \frac{(b-a) \times f}{W} \times 100 \times d
$$

where $a$ was amount $(\mathrm{mL})$ of $0.01 \mathrm{~N} \mathrm{NaOH}$ solution for filtrate of GBPs, $b$ was amount $(\mathrm{mL})$ of $0.01 \mathrm{~N} \mathrm{NaOH}$ solution for control, $d$ was dilution factor, $W$ was GBPs amount (mg) and $f$ was titer of $0.01 \mathrm{~N} \mathrm{NaOH}$ solution.

\section{pH}

Five grams of GBP was mixed with $20 \mathrm{~mL}$ of water and was homogenized at 10,000 rpm for $3 \mathrm{~min}$ using SMT process homogenizer (SMT Co. Ltd., Japan). The pH of GBPs was measured in triplicate using a $\mathrm{pH}$ meter $(\mathrm{pH} 900$, Precisa Co., Swiss).

\section{Water holding capacity}

Water holding capacity (WHC) of GBPs was determined (Hong et al., 2008). One gram of GBP was weighed and placed in a centrifuge tube along with gauze as an absorbent. The samples were centrifuged for $10 \mathrm{~min}$ at 3,000 rpm and $4^{\circ} \mathrm{C}$ in a refrigerated centrifuge (RC-3, SORVALL Co., USA). After centrifuging, the meat was removed from the tube and the weights of the centrifuge tubes before and after drying were determined. WHC was expressed as the percentage of moisture remaining in GBP samples. All measurements were carried out in triplicate.

\section{Total microbial count}

The total microbial count of GBPs stored at $5^{\circ} \mathrm{C}, 15^{\circ} \mathrm{C}$, and $25^{\circ} \mathrm{C}$ was determined at certain periods. One gram of sample was diluted in $9 \mathrm{~mL}$ pre-sterilized $0.85 \% \mathrm{NaCl}$ solution. One milliliter of bacteria solution was inoculated on the surface of a PCA plate. The plates were incubated at $37^{\circ} \mathrm{C}$ in incubator for $24-48 \mathrm{~h}$. Determination of $\mathrm{CFU} / \mathrm{g}$ was then carried out.

\section{Correlation of TTI, VBN, or total microbial count by Arrhenius equation}

Specially, the $a^{*}$-value of TTI, VBN and total microbial count of GBPs kept at various storage temperatures was calculated by Arrhenius equation. The Arrhenius equation defines the quantitative basis of the relationship between the activation energy $\left(E_{a}\right)$ and constant reaction rate $(k)$ as

$$
k=A \exp \left(-\frac{E_{a}}{R T}\right)
$$

where $R$ is the universal gas constant $(8.314 \mathrm{~J} / \mathrm{mol} \cdot \mathrm{K})$ and $T$ is absolute temperature $(\mathrm{K})$.

The $E_{a}$ of TTI, VBN, or total microbial count depending on various storage temperatures was calculated and plotted against the reciprocal of absolute temperature according to Eq. 1. The activation energy was then calculated from the logarithmic form of the Arrhenius equation. The parameter $E_{a}$ was calculated as a slope by plotting $\ln k$ as a function of $1 / \mathrm{T}$ according to the following equation.

$$
\ln k=\ln A-\frac{E_{a}}{R} \frac{1}{T}
$$

\section{Statistical analysis}

The data were analyzed by using one-way analysis of variance with storage periods. An analysis of variance was performed on all the variables using the General Linear Model (GLM) procedure (SAS 9.3, SAS Institute, USA). Differences among the means were compared using Tukey's Studentized Range (HSD) Test $(p<0.05)$.

\section{Results and Discussion}

\section{Color}

As described at sample preparation, the $\mathrm{a}^{*}$-value of the TTI or VBN were investigated as representative factors to indicate food spoilage in previous study. Through the previous study, all observation of GBPs' characteristics such as color, VBN, $\mathrm{pH}$, water holding capacity, and microbial test was finished when the $\mathrm{a}^{*}$-value of TTI was 20-25. Fig. 1 shows that changes in the $a^{*}$-value of both TTI and GBPs occurred during storage periods. TTI was kept at $25^{\circ} \mathrm{C}, 15^{\circ} \mathrm{C}$, or $5^{\circ} \mathrm{C}$ and color observation were finished after $24 \mathrm{~h}, 196 \mathrm{~h}$ and $288 \mathrm{~h}$ respectively according to the $a^{*}$-value (20-25). The total storage period was also subdivided into initial stage, middle stage, and final stage, because each sample temperature had different a storage 

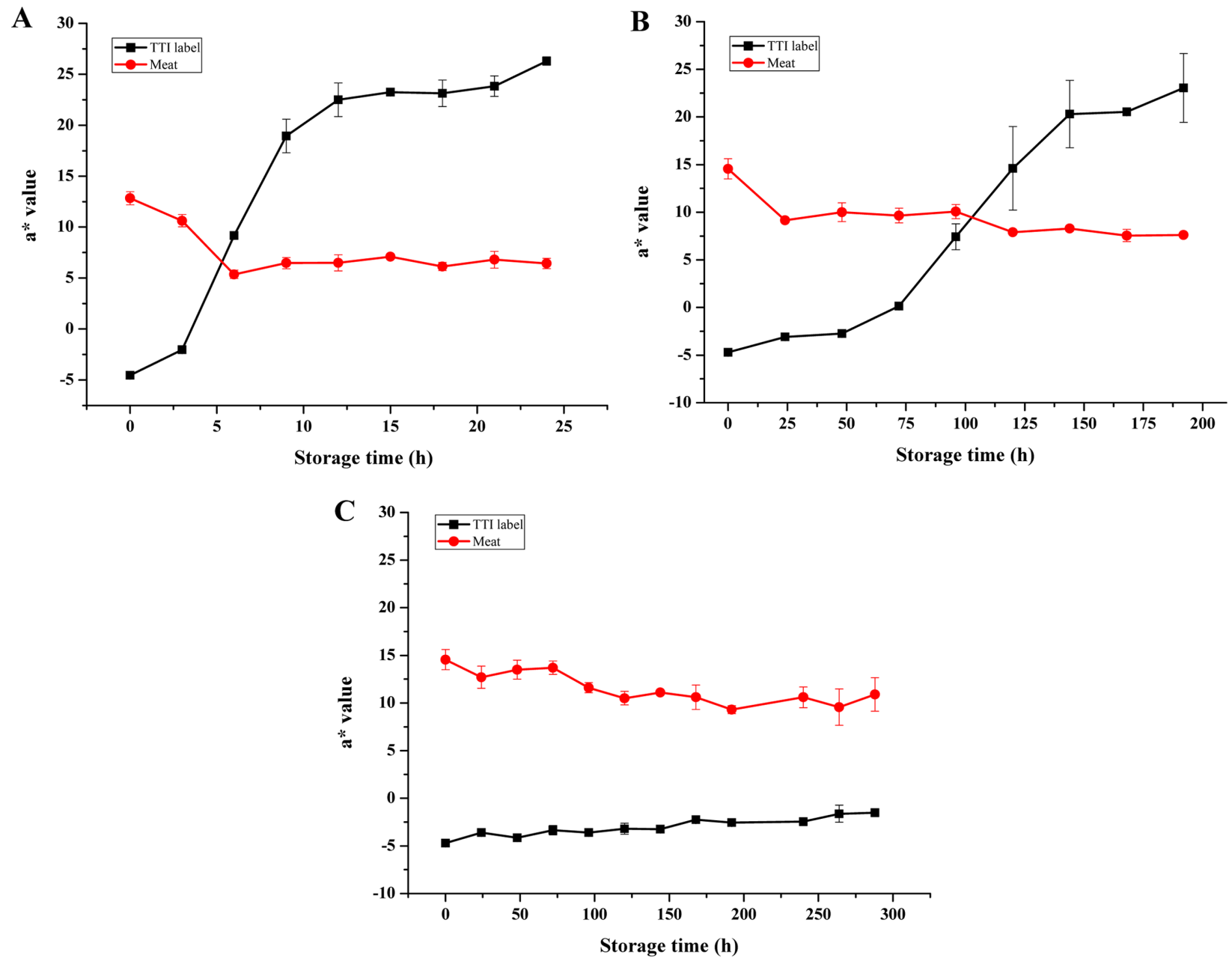

Fig. 1. $a^{*}$-value of TTI or meat as storage temperature (A: $\left.25^{\circ} \mathrm{C}, \mathrm{B}: 15^{\circ} \mathrm{C}, \mathrm{C}: 5^{\circ} \mathrm{C}\right)$. Vertical bars indicate standard deviations $(\mathrm{n}=3)$.

period (Table 1). The $a^{*}$-value of TTI only was significantly increased by raising the storage temperature at $25^{\circ} \mathrm{C}$ and $15^{\circ} \mathrm{C}(p<0.05)$, however, it was no difference among samples at $5^{\circ} \mathrm{C}$ storage temperature until VBN was over 20. There was no remarkable change in the $a^{*}$-value of GBPs kept at $15^{\circ} \mathrm{C}$ or $5^{\circ} \mathrm{C}$. The $b^{*}$-value of TTIs (Fig. 2) fluctuated during the storage period and the $b^{*}$-value of GBPs was quite stable at around 10 to $14(p>0.05)$. The $L^{*}$-value was not changed during storage periods (results not shown). Fig. 3 shows the real color of TTI and GBPs. TTI was changed green-yellow-red and GBPs were changed form blood red-light brown-deep blood red, in order of storage period, except for $5^{\circ} \mathrm{C}$ storage temperature. The

Table 1. Storage period of TTI and ground beef patty depend on storage temperature

\begin{tabular}{cccc}
\hline \hline Storage & \multicolumn{3}{c}{ Storage time $(\mathrm{h})$} \\
\cline { 2 - 4 } temperature $\left({ }^{\circ} \mathrm{C}\right)$ & Initial stage & Middle stage & Final stage \\
\hline 25 & 0 & 12 & 24 \\
15 & 0 & 96 & 192 \\
5 & 0 & 144 & 288 \\
\hline
\end{tabular}

$a^{*}$-value was the most changeable factor to indicate and predict the state of food quality, and moreover, consumers may easily recognize this TTI color change (Byeon et al., 2009; Chun et al., 2009; Kim et al., 2012a).

\section{Volatile basic nitrogen (VBN)}

The VBN value of GBPs depended on storage temperature $\left(5^{\circ} \mathrm{C}, 15^{\circ} \mathrm{C}\right.$, and $\left.25^{\circ} \mathrm{C}\right)$. VBN value was increased with storage period. It was quickly and steadily increased up to $22 \mathrm{mg} \%$ at $21 \mathrm{~h}$ with $25^{\circ} \mathrm{C}$ of storage temperature (Fig. $4 \mathrm{~A})$. Interestingly, $\mathrm{VBN}$ was dramatically increased at $75 \mathrm{~h}$ at $15^{\circ} \mathrm{C}$ and $5^{\circ} \mathrm{C}$ of storage temperature (Fig. 4B). The $a^{*}$ value was very low at the same time for both storage temperatures but the VBN of GBPs was already over $20 \mathrm{mg} \%$ at the $15^{\circ} \mathrm{C}$ storage temperature. A VBN value of $20 \mathrm{mg} \%$ is the prescribed point of spoilage according to the Korean Food Standards Codex. (Korea Food \& Drug Administration, 2012). Likewise $5^{\circ} \mathrm{C}$ storage temperature did not much affect the decomposition of GBPs, but VBN was increased up to $19.3 \mathrm{mg} \%$ during the storage period (Fig. 

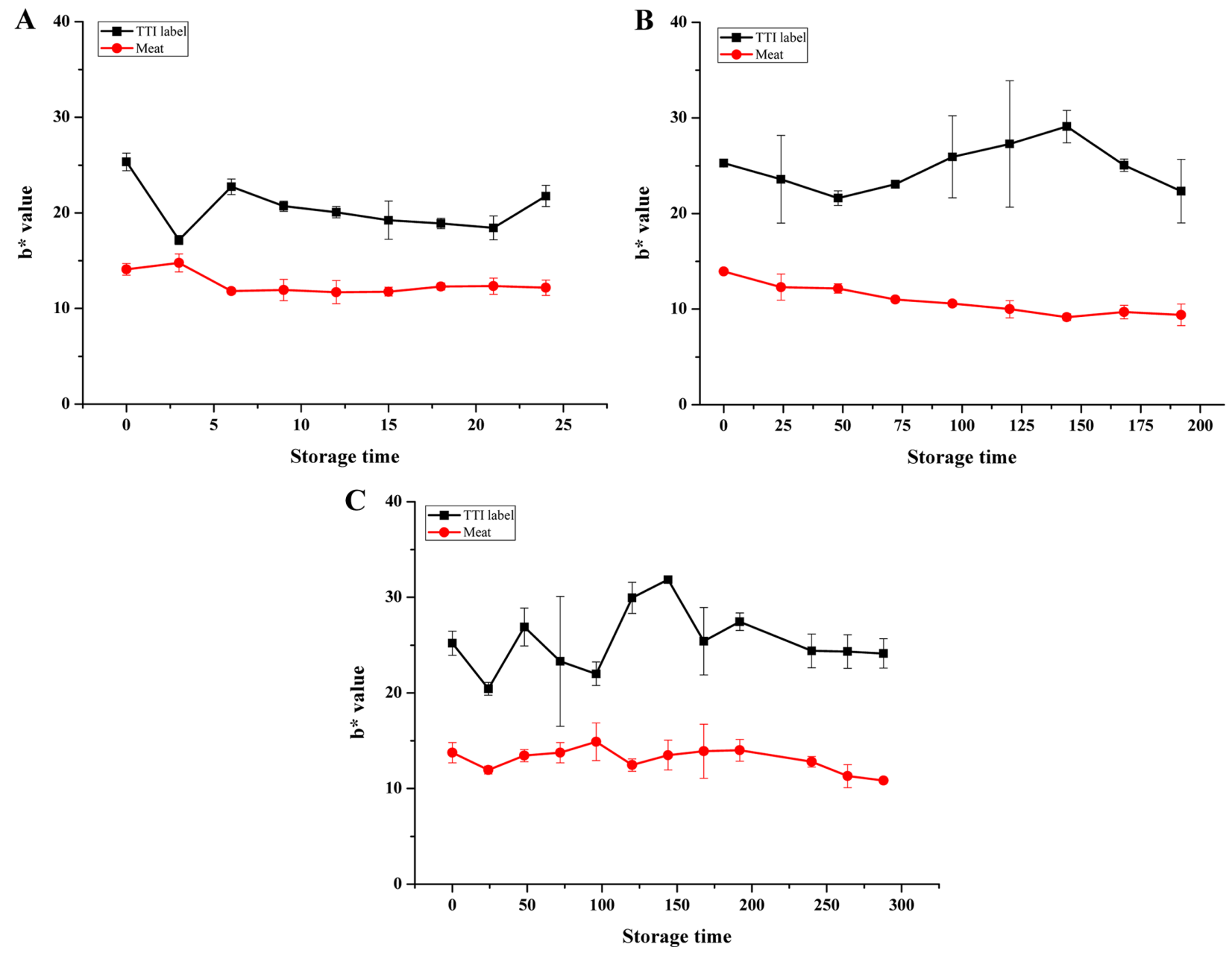

Fig. 2. $b^{*}$-value of TTI or meat as storage temperature $\left(\mathrm{A}: 25^{\circ} \mathrm{C}, \mathrm{B}: 15^{\circ} \mathrm{C}, \mathrm{C}: 5^{\circ} \mathrm{C}\right)$. Vertical bars indicate standard deviations $(\mathrm{n}=3)$.

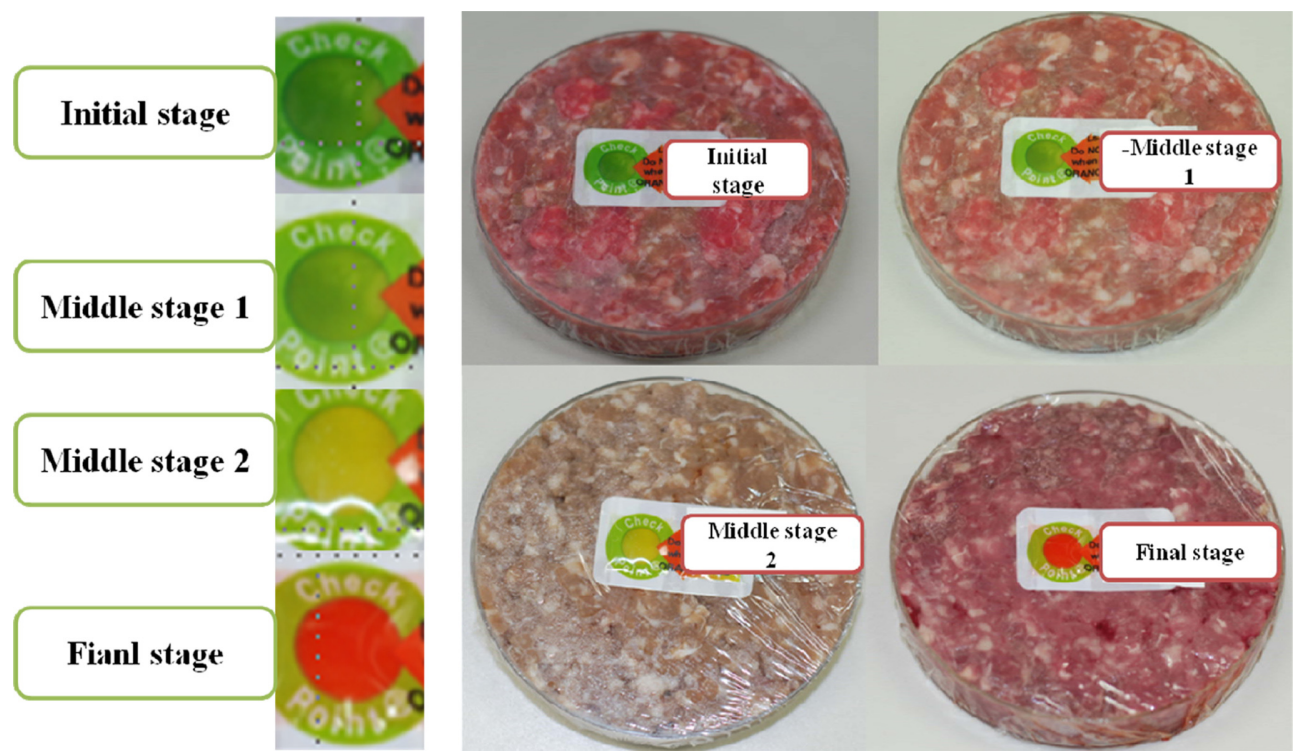

Fig. 3. Change in color of TTI and ground beef patty during storage periods.

4C). In this study, storage temperature was determined to age time.

be a more influential factor in increasing VBN than stor- 

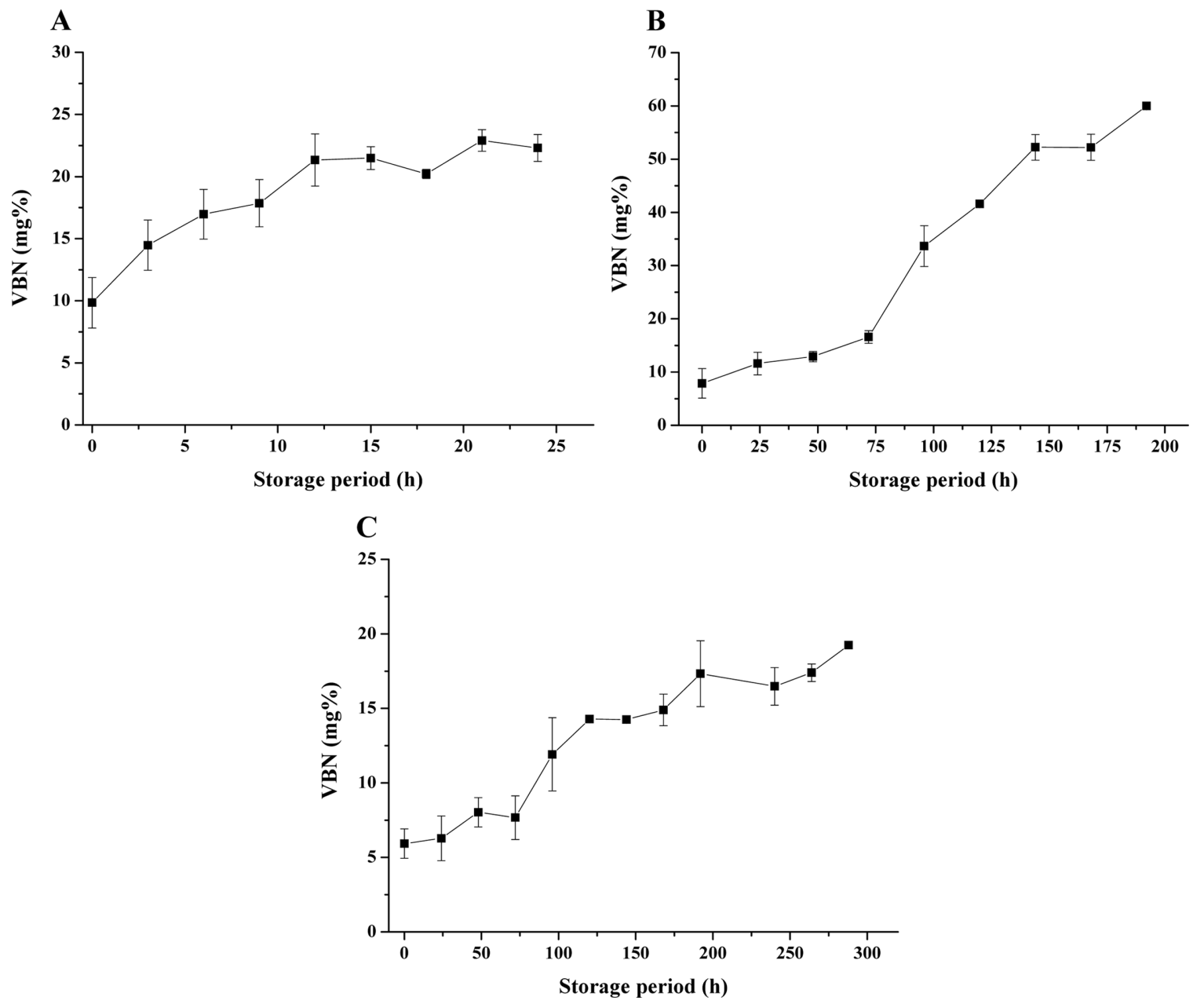

Fig. 4. VBN value of GBPs as storage temperature $\left(A: 25^{\circ} \mathrm{C}, \mathrm{B}: 15^{\circ} \mathrm{C}, \mathrm{C}: 5^{\circ} \mathrm{C}\right)$. Vertical bars indicate standard deviations $(\mathrm{n}=3)$.

\section{pH}

In this study, the $\mathrm{pH}$ of GBPs stored at $25^{\circ} \mathrm{C}$ ranged between 5 and 5.4 during storage periods and there was no big difference, but there was significant difference during storage period $(p<0.05)$ (Fig. 5). At $15^{\circ} \mathrm{C}$ storage temperature, initially the $\mathrm{pH}$ of GBPs was decreased and then increased up to 6.9 from middle stage to final stage. However, the $\mathrm{pH}$ of GBPs was not changed at $5^{\circ} \mathrm{C}$ during storage periods $(p>0.05)$. And the $\mathrm{pH}$ of GBPs stored at $15^{\circ} \mathrm{C}$ storage temperature as storage periods up to 6.77 . Fresh meat is generally regarded as having a $\mathrm{pH}$ of 5.5-5.8 during storage. When $\mathrm{pH}$ of meat reaches $\mathrm{pH} 8$, meat is regarded as being fully decomposed (Shin et al., 2006). GBPs kept at $15^{\circ} \mathrm{C}$ were almost spoiled at final stage of storage period based on their $\mathrm{pH}$. The GBPs kept at $5^{\circ} \mathrm{C}$ were not decomposed because of the low storage temperature. GBPs kept at $25^{\circ} \mathrm{C}$ were also not changed significantly because the storage periods was too short for sufficient chemical reaction of free amino acids and proteolysis by microorganism to take place, although the temperature was high

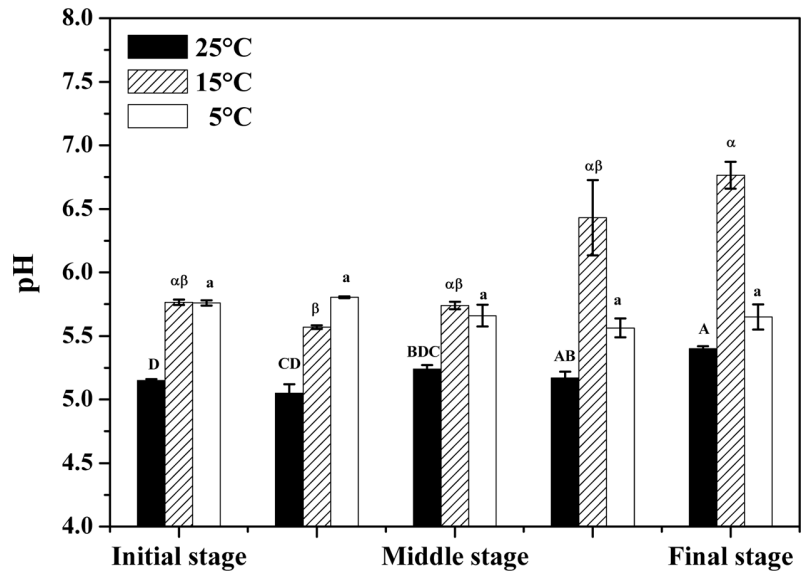

Fig. 5. pH of GBPs kept at various temperatures during storage periods. Vertical bars indicate standard deviations $(n=3)$. Means with different letters are significantly different $(p<0.05)$.

enough to affect other quality parameters of GBPs (Kim and Lee, 2011). Low storage temperature $\left(<5^{\circ} \mathrm{C}\right) \operatorname{did}$ not greatly affect $\mathrm{pH}$ as previously decomposed in several 
studies (Jeong et al., 2006; Jeremiah and Gibson 2001). Holley et al. (1994) also observed that the $\mathrm{pH}$ of fresh meat increased with the storage period. Storage time is more influential in increasing the $\mathrm{pH}$ of food compared to storage temperature.

In the study of Shin et al. (2006), the $\mathrm{pH}$ of beef loin or pork belly kept $2^{\circ} \mathrm{C}$ was coincide with the freshness indicator which was $\mathrm{pH}$ sensitive. Likewise, the $a^{*}$-value of TTI kept at $15^{\circ} \mathrm{C}$ was associated with $\mathrm{pH}$ in this study. However, other TTI treatments at $25^{\circ} \mathrm{C}$ and $5^{\circ} \mathrm{C}$ were not mat- ched with pH of GBPs. The $a^{*}$-value of TTIs kept $25^{\circ} \mathrm{C}$ rose quickly up to 26 with a red color, which indicated the spoilage stage, but the $\mathrm{pH}$ remained within the stable region, under 5.5. In the case of the $5^{\circ} \mathrm{C}$ TTI treatment, there was no change in either the $a^{*}$-value (Green TTI color) or the $\mathrm{pH}$ until the final stage, the point at which the VBN of GBPs was determined to be $20 \mathrm{mg} \%$.

\section{Water holding capacity}

Water holding capacity ranged from $65 \%$ to $75 \%$ (Fig. $6)$. Even if there was no significant difference among samples or storage periods $(p>0.05)$, samples stored at higher temperature had relatively higher water holding capacity during storage periods. Generally, water holding capacity is affected by storage temperature, rigor development, $\mathrm{pH}$ decline rate, ionic strength, and oxidation. In other words, isoelectric point ( $\mathrm{pI}$ ), low $\mathrm{pH}$, or high storage temperature induce a reduction in water holding capacity (Huff-Lonergan and Lonergan, 2005). In this study, although the $\mathrm{pH}$ of GBPs was maintained at $25^{\circ} \mathrm{C}$ was in pI zone, water holding capacity of GBPs was not changed significantly at all storage temperature furthermore it was even higher than others during storage periods $(p>0.05)$. At the final

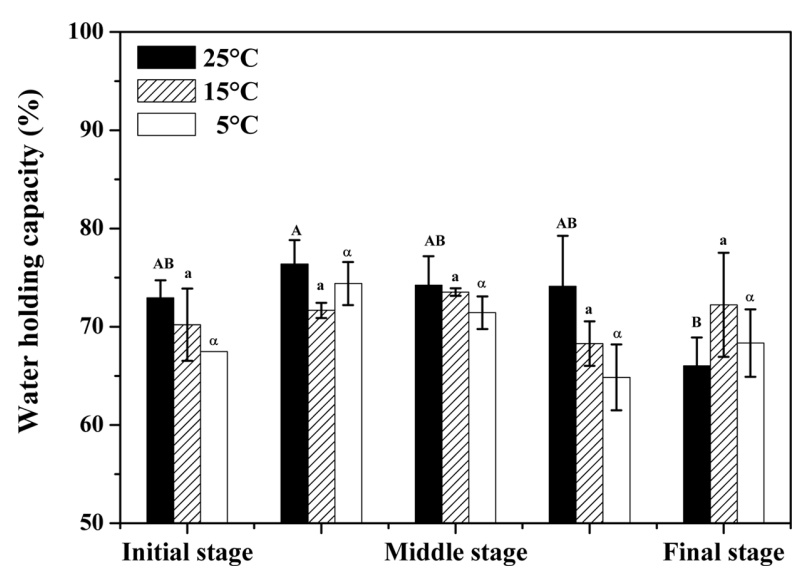

Fig. 6. Water-holding capacity GBPs kept at storage temperatures during storage periods. Vertical bars indicate standard deviations $(n=3)$. Means with different letters are significantly different $(p<0.05)$. storage period, although the $\mathrm{pH}$ of GBPs was stable during storage period at $25^{\circ} \mathrm{C}$, water holding capacity was decreased to $66 \%$, which was one of the lowest value. The reason was that the storage period $(24 \mathrm{~h})$ at $25^{\circ} \mathrm{C}$ was likely too short to affect the $\mathrm{pH}$ of the GBPs properties.

\section{Microbial observation}

Total microbial count of GBPs was counted during storage periods at $5^{\circ} \mathrm{C}, 15^{\circ} \mathrm{C}$, and $25^{\circ} \mathrm{C}(\mathrm{Fig}$. 7). Initial spoilage is important when we observe the behavior of microorganism. Although initial total microbial count was quite high to do microbial test in all GBPs, the difference was a clearly observed among GBPs in this study. As depicted in Fig. 7, microorganisms significantly and gradually increased at $15^{\circ} \mathrm{C}$ and $25^{\circ} \mathrm{C}$ storage temperature during storage periods $(p<0.05)$. Whereas the population of the $5^{\circ} \mathrm{C}$ treatment was relatively well controlled until $96 \mathrm{~h}$ storage however, it was dramatically increased after reaching 7
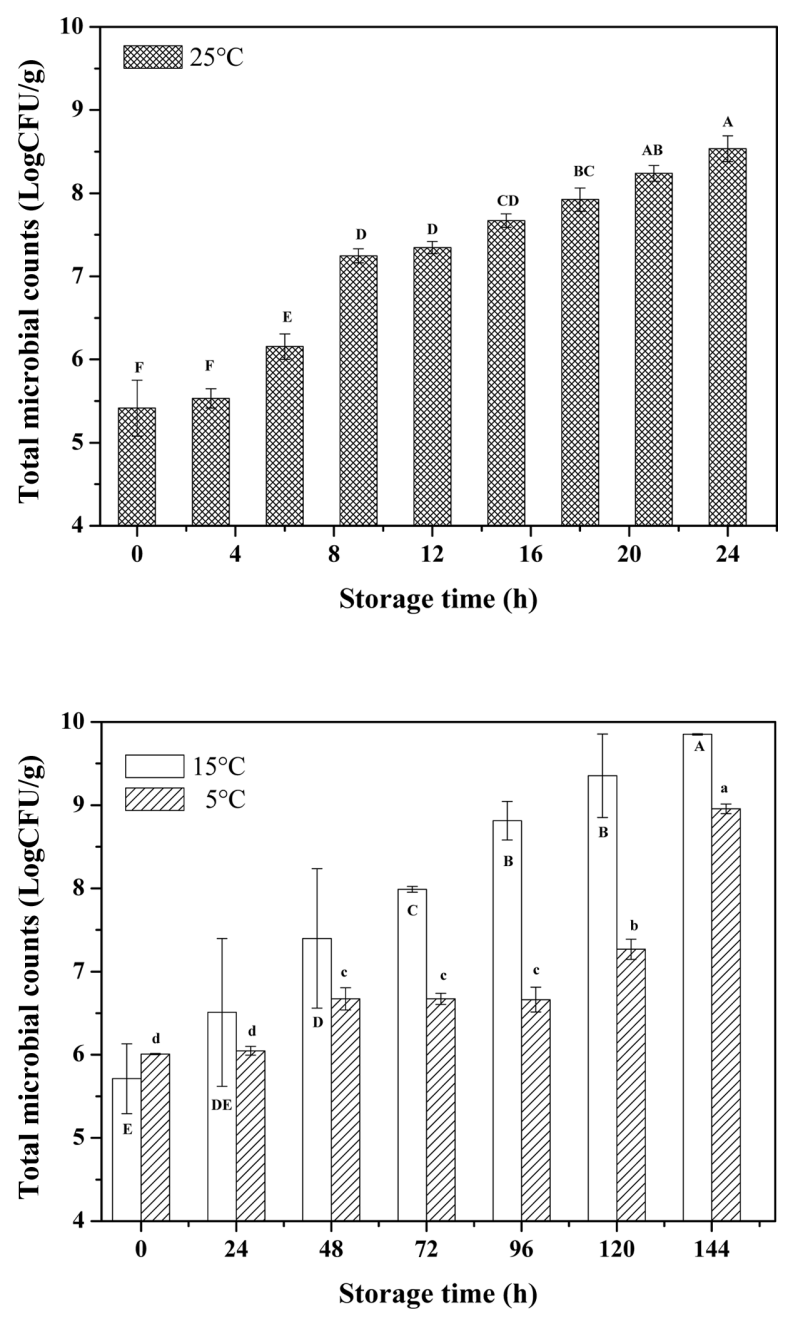

Fig. 7. Total microbial counts of GBPs during storage periods. Vertical bars indicate standard deviations $(n=3)$. Means with different letters are significantly different $(p<0.05)$. 
Log CFU/g $(p<0.05)$. In the study of Jeong et al. (2006) two grades of beef were stored at $1{ }^{\circ} \mathrm{C}$. Total bacterial count reached $8 \mathrm{Log} \mathrm{CFU} / \mathrm{g}$ at $28 \mathrm{~d}$ of storage. In the study of Shin et al. (2006), beef loin and pork belly were kept at $2^{\circ} \mathrm{C}$ for $10 \mathrm{~d}$. Total aerobic bacteria of beef loin was $8 \mathrm{Log}$ CFU/g at $10 \mathrm{~d}$. Jeong et al. (2006) and Shin et al. (2006) supposed that the increase of microorganisms was temperature dependant.

However, each GBP sample was determined as 7 to 8 Log CFU/g at the middle stage of VBN development. Generally, over $8 \mathrm{Log}$ CFU/g of microorganism make food to be decomposed and cause putrefied flavor which is unfavorable (KFDA, 2012). Therefore, the total microbial count cannot be observed through the basic senses until the meat is in the final stages of spoilage.

\section{TTI color, VBN or Total microbial count of meat, as} described by Arrhenius equation

Constant reaction rate $(k)$ and activation energy $\left(E_{a}\right)$ of TTI (color, $a^{*}$-value), quality of GBPs (VBN) or microbial growth (total microbial count) depend on storage temperature, and this was calculated through the Arrhenius equation (Fig. 8 and Table 2). The $k$ of TTI color, VBN,

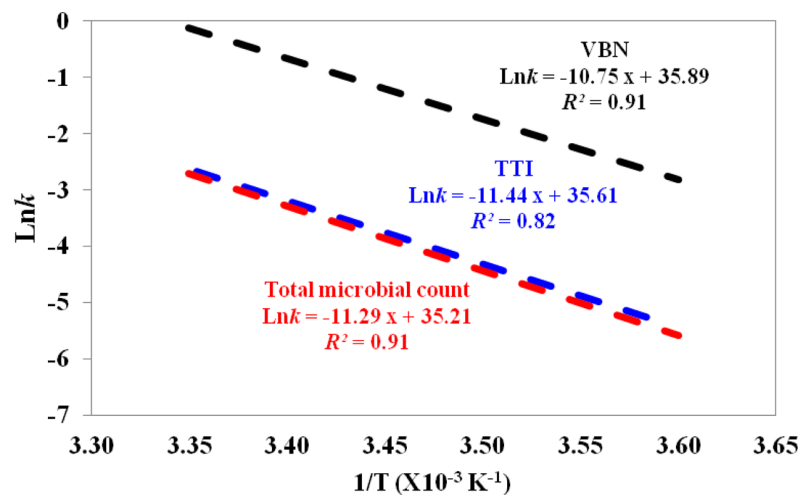

Fig. 8. Arrhenius plot of the constant reaction rate $(k)$ of TTIs with various storage temperatures.

Table 2. Arrhenius parameters, activation energy $\left(E_{\mathrm{a}}\right)$ and Constant reaction rate $(k)$ of TTI, VBN or total microbial count with different storage temperature

\begin{tabular}{ccccc}
\hline \hline & $T\left({ }^{\circ} \mathrm{C}\right)$ & $k$ & $E a(\mathrm{~kJ} / \mathrm{mol})$ & $\mathrm{R}^{2}$ \\
\hline \multirow{2}{*}{ TTI } & 25 & 0.099 & & \\
& 15 & 0.008 & 95.1 & 0.819 \\
& 5 & 0.006 & & \\
VBN & 25 & 0.685 & & \\
& 15 & 0.396 & 92.6 & 0.910 \\
\hline Total & 5 & 0.048 & & \\
microbial & 25 & 0.090 & & \\
count & 5 & 0.011 & 93.9 & 0.909 \\
\hline
\end{tabular}

and total microbial count each developed at increasing rates with increasing storage temperature. The $k$ of VBN was highest at every storage temperature. As a result of VBN determinations, every GBPs started to be spoiled at near middle stage of each samples in this study. The $E_{a}$ of TTI, VBN, and total microbial count were similar as 95.12, 92.60 or $93.90 \mathrm{~kJ} / \mathrm{mol}$, respectively. The $E_{a}$ of $\mathrm{VBN}$ and microbial growth were in the range of typical $E_{a}$ values for food quality losses (Labuza, 1982). If there is more than $\pm 25 \mathrm{~kJ} / \mathrm{mol}$ of $E_{a}$ differences between food and TTI, the accuracy of indicator is regarded as poor (Park et al., 2013; Taoukis, 2001; Wanihsuksombat et al., 2010). Moreover, the $E_{a}$ of food is changed depending on the temperature interval (Wanihsuksombat et al., 2010). In this study, even though $E_{a}$ was similar between the TTI and the determined quality parameters of GBPs, it did not coincide with the decomposition or spoilage of GBPs. This problem has been a major disadvantage of enzymatic TTIs for food shelf life in the past, but such systems may best fitted to their optimum foods as well as reverse engineered to some degree. (Byeon et al., 2009; Kim et al., 2012a; Kim et al., 2012b; Park et al., 2013; Taoukis et al., 1999).

\section{Conclusions}

It was investigated whether a TTI was appropriate for the prediction of quality of GBPs, such as VBN or total microbial count at $25^{\circ} \mathrm{C}$. However, there was insufficient correlation with the color change of the TTI at $5^{\circ} \mathrm{C}$ and at $15^{\circ} \mathrm{C}$, although the interrelation between the TTI and the index of GBPs quality such as $\mathrm{pH}, \mathrm{VBN}$, and total microbial count was slightly observed. In other words, one type of TTI could not indicate quality of GBPs kept in various storage conditions. It has been suggested that TTIs should be designed individually depending on storage temperature, time, and the type of meat. Moreover, meat quality must be investigated because it may not be possible to simultaneously match various attributes of meat quality with the reaction of a single TTI.

\section{Acknowledgements}

This work was performed as a research project of the iPET (Korea Institute of Planning and Evaluation for Technology of Food, Agriculture, Forestry and Fisheries) supported by Ministry for Food, Agriculture, Forestry and Fisheries of Korea. This study was also partially supported by the SMART Research Professor Program of Konkuk University, Seoul, Korea. 


\section{References}

1. Bobelyn, E., Hertog, M. L. A. T. M., and Nicolaï, B. M. (2006) Applicability of an enzymatic time temperature integrator as a quality indicator for mushrooms in the distribution chain. Postharvest Biol. Technol. 42, 104-114.

2. Bruckner, S., Albrecht, A., Petersen, B., and Kreyenschmidt, J. (2013) A predictive shelf life model as a tool for the improvement of quality management in pork and poultry chains. Food Control 29, 451-460.

3. Byeon, K. E., An, S. R., Shim, S. D., Lee, J. Y., Hong, K. W., Min, S. G., and Lee, S. J. (2009) Investigation on beef quality indicator of off-flavor development during storage. Korean $J$. Food Sci. An. 29, 325-333.

4. Chun, J. Y., You, S. K., Kim, J. M., Surassmo, S., Bejraph, P., and Min, S. G. (2009) Changes in TTI-value of model beef depending on time-temperature and dimension. In The annual conference of 41st Korean Society for Food Science of Animal Resources, Korean Society for Food Science of Animal Resources. Korea.

5. Claeys, W. L., Van Loey, A. M., and Hendrickx, M. E. (2002) Intrinsic time temperature integrators for heat treatment of milk. Trends Food Sci. Tech. 13, 293-311.

6. Ellouze, M., Gauchi, J. P., and Augustin, J. C. (2011) Use of global sensitivity analysis in quantitative microbial risk assessment: Application to the evaluation of a biological time temperature integrator as a quality and safety indicator for cold smoked salmon. Food Microbiol. 28, 755-769.

7. Giannakourou, M. C. and Taoukis, P. S. (2002) Systematic application of time temperature integrators as tools for control of frozen vegetable quality. J. Food Sci. 67, 2221-2228.

8. Holley, R. A., GariÉPy, C., Delaquis, P., Doyon, G., and Gagnon, J. (1994) Static, controlled $\left(\mathrm{CO}^{2}\right)$ atmosphere packaging of retail ready pork. J. Food Sci. 59, 1296-1301.

9. Hong, G. P., Ko, S. H., Choi, M. J., and Min, S. G. (2008) Effect of glucono- $\delta$-lactone and $\kappa$-carrageenan combined with high pressure treatment on the physico-chemical properties of restructured pork. Meat Sci. 79, 236-243.

10. Huff-Lonergan, E. and Lonergan, S. M. (2005) Mechanisms of water-holding capacity of meat: The role of postmortem biochemical and structural changes. Meat Sci. 71, 194-204.

11. Jeong, G. G., Park, N. Y., and Lee, S. H. (2006) Quality characteristics of high and low grade hanwoo beef during storage at $1^{\circ} \mathrm{C}$. Korean J. Food Sci. Technol. 38, 10-15.

12. Jeremiah, L. E. and Gibson, L. L. (2001) The influence of storage temperature and storage time on color stability, retail properties and case-life of retail-ready beef. Food Res. Int. 34, 815-826.

13. Jin, S. K., Kim, I. S., and Hah, K. H. (2002) Changes of pH, drip loss and microbes for vacuum packaged exportation pork during cold storage. Korean J. Food Sci. An. 22, 201-205.

14. Kim, B. S. and Lee, Y. E. (2011) Effect of antioxidant on quality of ground beef during the refrigeration storage. Korean $J$.
Food Nutr. 24, 422-433.

15. Kim, K., Kim, E., and Lee, S. J. (2012a) New enzymatic timetemperature integrator (TTI) that uses laccase. J. Food Eng. 113, 118-123.

16. Kim, M. J., Jung, S. W., Park, H. R., and Lee, S. J. (2012b) Selection of an optimum $\mathrm{pH}$-indicator for developing lactic acid bacteria-based time-temperature integrators (TTI). J. Food Eng. 113, 471-478.

17. Korean Food Standards Codex. (2012) Korea Food \& Drug Administration. Korea.

18. Labuza, T. P. (1982) Shelf-life dating of foods, Westport, Food and Nutrition Press.

19. Orta-Ramirez, A. and Smith, D. M. (2002) Thermal inactivation of pathogens and verification of adequate cooking in meat and poultry products. In: Advances in Food and Nutrition Research, Poole, R. K. (ed) Academic Press., NY, 44, 147-194.

20. Park, H. J., Shim, S. D., Min, S. G., and Lee, S. J. (2009) Mathematical simulation of the temperature dependence of time temperature integrator (TTI) and meat qualities. Korean $J$. Food Sci. An. 29, 349-355.

21. Park, H. R., Kim, K., and Lee, S. J. (2013) Adjustment of Arrhenius activation energy of laccase-based time-temperature integrator (TTI) using sodium azide. Food Control 32, 615-620.

22. Shin, H. Y., Ku, K. J., Park, S. K., and Song, K. B. (2006) Use of freshness indicator for determination of freshness and quality change ofbeef and pork during storage. Korean J. Food Sci. Technol. 38, 325-330.

23. Smolander, M., Alakomi, H. L., Ritvanen, T., Vainionpää, J., and Ahvenainen, R. (2004) Monitoring of the quality of modified atmosphere packaged broiler chicken cuts stored in different temperature conditions. A. Time-temperature indicators as quality-indicating tools. Food Control 15, 217-229.

24. Taoukis, P. S. (2001) Modelling the use of timee temperature indicators in distribution and stock rotation. In: Food Process Modelling, Tijskens, L. M. M., Hertog, M. L. A. T. M., and Bicolai, B. M. (eds) CRC Press, Washington, DC, 402-431.

25. Taoukis, P. S., Koutsoumanis, K., and Nychas, G. J. E. (1999) Use of time-temperature integrators and predictive modelling for shelf life control of chilled fish under dynamic storage conditions. Int. J. Food Microbiol. 53, 21-31.

26. Vaikousi, H., Biliaderis, C. G., and Koutsoumanis, K. P. (2009) Applicability of a microbial time temperature indicator (TTI) for monitoring spoilage of modified atmosphere packed minced meat. Int. J. Food Microbiol. 133, 272-278.

27. Van Loey, A., Hendrickx, M., De Cordt, S., Haentjens, T., and Tobback, P. (1996) Quantitative evaluation of thermal processes using time-temperature integrators. Trends Food Sci. Tech. 7, 16-26.

28. Wanihsuksombat, C., Hongtrakul, V., and Suppakul, P. (2010) Development and characterization of a prototype of a lactic acid-based time-temperature indicator for monitoring food product quality. J. Food Eng. 100, 427-434.

$\overline{\text { (Redeived 2013.4.17/Revised 2013.6.21/Accepted 2013.7.5) }}$ 